\title{
Cadets' axiological basics of formation of civil identity
}

\author{
Liubov Khoronko ${ }^{1, *}$, Tatyana Tskvitariya ${ }^{2}$, and Igor Akhanov ${ }^{3}$ \\ ${ }^{1}$ Don State Technical University, Southern Federal District, 344003, Gagarin Square 1. Rostov on \\ Don, Russian Federation \\ ${ }^{2}$ Rostov State Medical University, 344022, Southern Federal District, Nakhchivansky lane, 29, \\ Rostov on Don, Russian Federation \\ ${ }^{3}$ Southern Federal University, Southern Federal District, 344000, Bolshaya Sadovaya str., 105/42, \\ Rostov on Don, Russian Federation
}

\begin{abstract}
The article considers the problems of cadets' education, which has found their justification in the views of modern scientists, including representatives of psychological and pedagogical direction. The analysis of works of the main modern authors relating to the topic of formation of civil identity is carried out. The analysis has shown the peculiarities of the axiological foundations of the formation of civil identity among cadets in the modern system of Russian education. The analysis of the revealed values on the problem of formation of civil identity among cadets in the conditions of modern civil society is also presented.
\end{abstract}

\section{Introduction}

Modern scientific and pedagogical discourse in Russia shows that many researchers who have come to realize the need of developing the concept of "civil identity", there is no single point of view concerning the understanding of this phenomenon.

On the one hand, the concept of "civil identity" is interpreted as a person's awareness of his belonging to the community of citizens of a certain State on a General cultural basis. On the other hand, it is a phenomenon of individual consciousness, a sign of civil community, characterizing it as a collective subject. In his opinion, civil identity has a certain personal meaning. At the same time, civil identity is not identical to citizenship. Today society does not offer the younger generation a model of full-fledged social development, ways of acquiring civic identity. There is no clear distinction between traditions that are strong and do not lose their relevance in today's realities and those that have gone into the historical baggage. However, as in any educational system, in the modern educational process there are traditions from the historical past and actual goals and objectives of the day. The formation of civic identity also occurs through the development of goals and ideas by the young generation through the implementation of an active social position. At present, education (civic, patriotic, legal, spiritual and moral) is considered as the most important institution for the formation of the civic identity of Russians. The formation of civic identity is not limited to the implementation of state programs, information campaigns,

\footnotetext{
* Corresponding author: soiskatel2005@yandex.ru
} 
civic education, but is determined by the individual's need to be a citizen and requires personal efforts. Researchers come to the conclusion that civic identity is not so much a project of the state and other social institutions as an auto-project of a person. In this case, the citizen acts as a subject, the author of civic identity, and not an object of civic education, managerial influence in general. To create the upbringing of the phenomenon of civil identity, it is necessary to form a special system of his upbringing, education, selection, placement, personnel, as well as a special system of ethical norms of his behavior and social security measures, which are implemented in educational institutions of primary military education. [1-3]

There is an opinion that the most important constitutive element of the civil community in the civil identity, contributing to the integration of the population of the country and is the key to the stability of the state [4].

Civil identity is formed in the conditions of educating future officers in specialized educational institutions with a focus on state socialization and responsibility for the fate and future of the country [5].

Magranov, A.S. understands the awareness of the individual of his belonging to any community of citizens under civil identity The structure of civic identity includes three main elements: cognitive - knowledge about belonging to a given social community, value the presence of a positive or negative attitude to the fact of belonging and emotional acceptance or rejection of a civic community as a membership group, as a result of the action of the first two [6], evaluates civil identity as a politically-oriented category, in the content of which the political and legal competence of the individual, political activity, civic participation, sense of civic community are distinguished [7].

Investigating the problem, scientists note that considers the civil identity as the cultural element of citizenship, or civil culture considers civic identity as an element of civic culture, or civic culture The formation of civic identity is not a single act, but a series of interrelated personal choices. Civic identity is not a static formation, not a set of invariable characteristics. The author notes that when considering the main trends in the development of modern Russian society, it should be noted that the values and guidelines that previously guided the actions of people have been rejected, while the new order of interaction has not yet been developed. The identity of a modern person is quite plastic, and the process of its formation can be compared to the modeling of a person himself. In the conditions of the complication of the picture of social reality, the development of Russian society as an open system, the individual is forced to choose his life path from a variety of perspectives, constantly adjusting his life goals, motives of activity, value attitudes. [8].

Research authors represents the civil identity as identity of a person to the status of citizen, preparedness and ability to perform the duties, connected with existence of citizenship, to use the rights, to take an active part in life of the State As a factor in the formation of civic identities among the new generation, it is proposed to use creative and innovative activities, preferably of a long-term nature. Such activity meets the psychological and age characteristics and interests of the pupils, and also allows you to build the learning process through a conscious understanding of information and ideas about their place in society, in the history of their people. [9-10].

\section{Materials and Methods}

The object of the research is the materials of open scientific and practical conferences on the problems of pre-University education, the texts of monographic studies and defended theses on the topic of formation of civil identity of the younger generation.

Research methods-theoretical research methods; analysis, synthesis, comparison, interpretation, generalization, content analysis, cluster analysis. 
The Logic of the research requires studying of the conceptual provisions that determine the novelty of strategic approaches to the system of cadets' education in Russia on the basis of studying the historical process of formation of cadets' educational model, as well as, modern works on the investigated problem.

\section{Results and Discussions}

The fact, which is common in the previous definitions, is that civil identity is a reflection of the meaning of the individual's life orientations in the democratic society. The basic foundations of this type of General education, the rules and norms of a democratic society, as well as, personal worldview experience are being formed on the basics of principles of training and education in the conditions of cadets' education. Improving the education system by introducing new requirements, norms, pedagogical technologies of a humanistic nature in order to form students' basic national values, spiritual traditions, awareness of the value of other people, a sense of personal responsibility for the Fatherland and strengthening faith in Russia. [11-12]

Civic identity fixes the unity of the interests of the individual with a given social community and thus performs both a protective function and the function of self-realization and self-expression, allows influencing the civil society. Civic identity, as the fundamental basis of personal worldview, is based on the terminal and instrumental values characteristic of the younger generation.

The study of this problem revealed that cadets are dominated by such values as the value of life position. It appears in the correlation of the personality of their expectations, orientations and actions with certain ideals, values and meanings on the basis of conscious choice of a certain position, making a responsible decision. Each person can have his own system of values, which in this hierarchy are built in a certain relationship. What is the combination of values included in the structure of value orientations, what is the degree of their preference relative to others, depends on what goals of life a person's activity is directed to. [13] It is correlated with the understanding of the stable position of personal attitudes, values and meanings, because they determine, on the one hand, the inner world of the personality, its feelings and experiences, on the other hand motivational and regulatory correlations that determine the real behaviour of the personality.

In the course of studying the problem, it is established that human values are closely related to his self-consciousness and self-determination in the world around him. That is why a person's recognition of basic values and adherence to them in real life can serve as important criteria for a formed civic identity. The orientation of a person to certain values directly influences his activity (through goal attitudes) and behavior (through attitude to reality - the object of orientation). Therefore, in the process of educating students' patriotism, it becomes important to diagnose knowledge about the value orientations of the individual. [14-15]

One of the tasks of modern education is to form the cadets' ability to relate themselves to civil society, to see themselves as a citizen of their country, to feel a sense of pride in their homeland. The cadet, as a future officer, must have an experience of civilian behavior.

According to experienced specialists in the field of civic education, the complex of civic qualities of children and adolescents is a complex system. It can be characterized as a combination of the following components:

- civic duty as a conscious system of civil requirements of society and the state, caused by the needs of social necessity and specific goals and objectives of the historical stage of development;

- civic responsibility as a personality trait, characterized by the desire and ability to assess their behavior in terms of benefit or harm to society, measure their actions with the 
prevailing requirements in society, norms, laws, correlate needs with real opportunities, guided by the interests of social progress;

- civic conscience as the ability of a person to self-control, manifested in the form of awareness, experience of a person of his attitude to the norms of the social environment, society and the conformity of his actions to these norms;

- civic engagement as a measure of a person's participation in solving socially significant problems, manifested in attitudes towards society, labor and property, towards other people, towards oneself; respect and acceptance of rights and responsibilities;

- civic consciousness as a way of relating to objective reality, mediated by the corresponding form of human activity;

- respect for the laws of the state as the ability to perceive laws and readiness to comply with them;

- a sense of patriotism and internationalism as a specific feeling of love for the Motherland, activities aimed at serving the interests of the Fatherland, while respecting the sovereignty and national pride of other peoples.

To determine the level of formation of the components of civic identity, questionnaires were selected, based on the methodology of ranking the values of M. Rokich, containing blocks of questions dedicated to the diagnosis of the level of formation of civic values.

Values are the result of an individual's entry into society, a person is not born with them, but acquires them throughout his life in the process of socialization. Values are always socially determined, that is, they depend on the society in which a person develops and in which he lives, they are not stable, they can change significantly throughout the life of an individual, this is due both to the natural characteristics of age development (for example, very strong changes in value system occur during puberty and other periods of age crises), and with the personal life experience of each person, as well as the socio-political and economic conditions of his life.

We performed a ranking of values on the" test of value orientations " by M. Rokich, which identifies two classes of values to find out how adequately students define their core values:

1. terminal-beliefs that the ultimate goal of individual existence is worth striving for, a set of 18 values is presented;

2. instrumental-the belief that a particular course of action or personality trait is preferable in any situation, a set of 18 values is presented. In order to identify the predominance of terminal and or instrumental orientation, we performed a study among the same respondents according to the standard method by M. Rokich. The results of the study are presented in diagrams and reflect the all-Russian trends among students of different ages to the present day. The dominance of instrumental values over terminal values is revealed, which indicates a decrease in the importance of life-sense orientations among cadets. However, the situation in this respect is not critical, since the gap in indicators between these parameters is small and it is 7.1 points for terminal values and 7.45 for instrumental ones. 


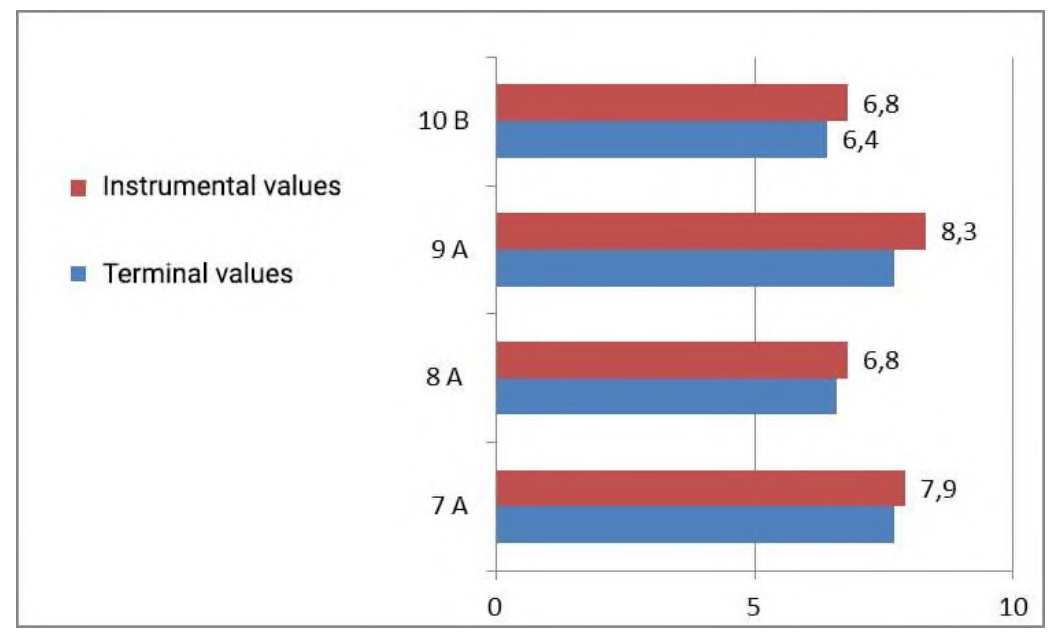

Fig. 1. Dynamics of General indicators of terminal and instrumental values.

The analysis of ranking the values by the method of M. Rokich revealed that the most priority values for cadets in the block of terminal values are the presence of good and faithful friends, development, self-confidence, happy family life, active life, love.

The most significant for the studied two groups of respondents: the cadets chose the value of the family as the most significant. In the second and third positions, the values "materially secured life" and the values "friends" are located with the same result. The value "materially secured life" took the seventh position among the values they allocated,

When determining the instrumental values that are significant for cadets as values means and by which they are guided in understanding civic identity, the value of "education" and "accuracy" as a strategy for obtaining high-quality professional education received high positions among all respondents. They position this value with an understanding of responsibility, being a man of his word, ambition, commitment. The high status of the cadets has the value of "open-mindedness", "honesty" and "efficiency in business", "sensitivity".

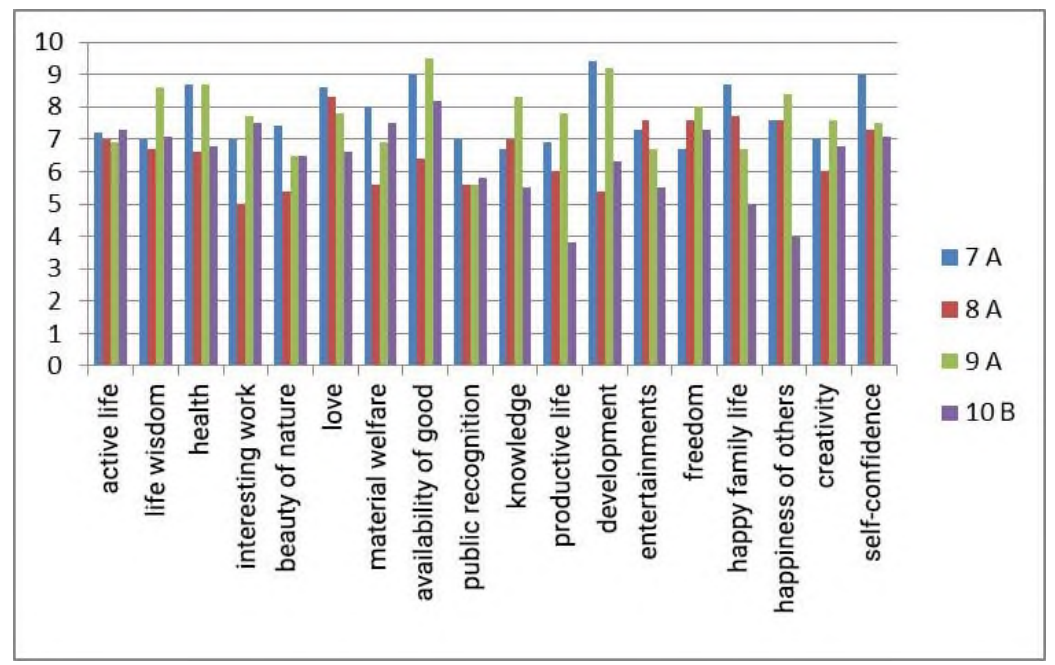

Fig. 2. Distribution of answers on the block Terminal values (M. Rokich's technique) 
The block of instrumental values testifies to prevalence of importance in consciousness of cadets of such values as self-control, education, rationalism, responsibility, efficiency, education.

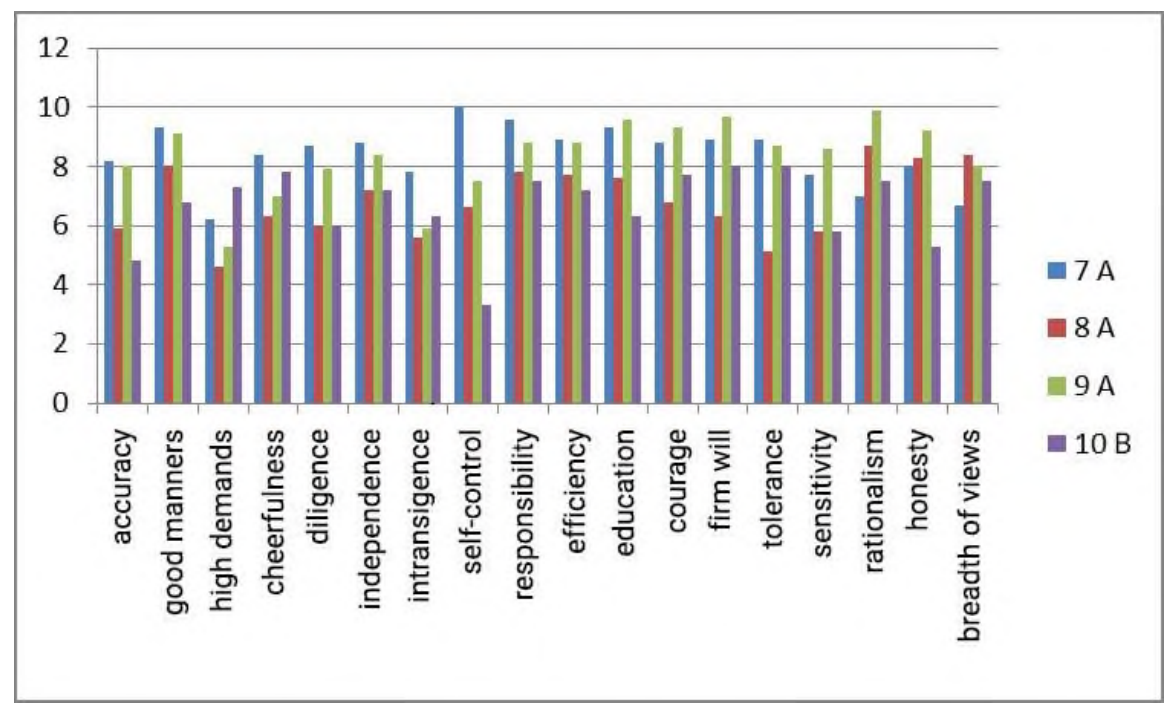

Fig. 3. Distribution of answers on the block Instrumental values (M. Rokich's technique)

\section{Conclusions}

A wide study of the issue of the formation of cadets' civil identity, we came to the conclusion that this is a socio-pedagogical problem, the solution of which is by creating conditions for the pupils to understand themselves as a citizen of their country and civil society, and to realize their belonging to a civil community.

The study of axiological values showed the importance of the formation of cadets' civil identity as a result of the process of relating themselves to the civil community, its values and norms, which brings the student to the awareness of their identity on the basis of understanding the rights and obligations realized in the process of participation in the life of the civil community.

Based on the analysis of modern scientific concepts in practical education, we came to the conclusion to create a practice-oriented concept of the formation of civil identity of cadets, the leading idea of which is the idea of civil culture based on terminal and instrumental values.

One of the directions of the process of forming civic identity among the younger generation is to familiarize cadets with values. This is done through training cadets to resolve moral dilemmas, which is carried out through the enrichment of the categorical structures of their thinking in the context of civic behavior and activities. This is also facilitated by the normalization of relations between young people and other people within the framework of expedient civic activity, which involves the choice of relevant landmarks in the field of civic activity. 0

The result of the scientific discourse in the practical plan of studing, confirmed the initial hypothesis of the study that the process of formation of civil identity is formed in cadets on the basis of ideas (knowledge) about the categories and concepts of "identity", "citizen", "civic community", "citizenship" and about terminal and instrumental values, familiarization with which expands the axiological field of personal self-determination. 


\section{References}

1. N. V. Volynkina, V. V. Gladkikh, T. V. Larina, Prospects for Science and Education, 45(3), 87-954 (2020)

2. I. Valor-Segura, G. Navarro-Carrillo, N. Extremera, M. I. Roldán-Bravo, A. RuizMoreno, Frontiers in Psychology, 11, 875 (2020) doi: 10.3389/fpsyg.2020.00875

3. L. Filosa, G. Cepale, E. Perinelli, A. Coscarelli, G. Alessandri, European Journal of Psychological Assessment, a000593, 154-157 (2020) doi: 10.1027/1015-5759/a000593

4. G. S. Denisova, A. V. Denisova, E. I. Litvinenko, E. V. Susimenko, Man in India, 97(11), 543-562, (2017)

5. P. N. Ermakov, I. V. Abakumova, O. Fedotova, D. P. Shchetnina, International Journal of Environmental and Science Education, 11(18), 10829-10837 (2016)

6. A. S. Magranov, L. S. Detochenko, Sociological research, (8), 108-116 (2018) doi: 10.31857/S013216250000766-5

7. R. G. Galihuzina, Social Sciences (Pakistan), 10(7), 1877-1880 (2015) doi: 10.3923/sscience.2015.1877.1880

8. S. I. Zamaletdinova, G. K.Akhmetshina, L. R. Khrapal, Review of European Studies, 1 7(5), 193-199 (2015) doi: 10.5539/res.v7n5p193

9. R. Boivin, C. Faubert, A. Gendron, B. Poulin, Police Practice and Research, 21(1), 4961 (2020) doi: 10.1080/15614263.2018.1555480

10. N. I. Bolshunova, A. V. Spirin, A. N. Pomerlyan, A. V. Andronov, A. G. Chaporgin, Prospects for Science and Education, 45(3), 336-349 (2020)

11. E. A. Caspar, De S. B. Lo Magalhaes, A. Pedro, ARMED FORCES \& SOCIETY, 11(1), 4366, (2020)

12. C. G. L. Nerstad, R. Buch, A. Dysvik, Frontiers in psychology, 11, 1326 (2020)

13. M. V. Shakurova, International Education Studies, 8(1), 125-132 (2015) doi: 10.5539/ies.v8n1p125

14. A. Taghva, S. T. S. Asl, A. M. Rahnejat, , Iranian journal of psychiatry and behavioral sciences, 14(2), e86477,(2020)

15. A. N. Yegorov, Perm University Herald - History, 48(2), 110-121 (2020) 